\title{
Famílias de himenópteros parasitoides na Serra do Japi, Jundiaí, São Paulo, Brasil
}

\section{Families of hymenoptera parasitoids in Serra do Japi, Jundiaí, São Paulo, Brazil}

\author{
Jober Fernando Sobczak ${ }^{1 *}$, João Vasconcellos Neto²
}

RESUMO: Este estudo teve como objetivo realizar um levantamento das famílias de himenópteros parasitoides em área de mata atlântica da Reserva Municipal Serra do Japi (2313' 52,24”S, $46^{\circ} 56^{\prime} 09,00^{\prime \prime}$ O), Jundiaí, São Paulo, Brasil. Foram coletados 1.300 himenópteros parasitoides de oito superfamílias e de 23 famílias. A coleta foi realizada durante cinco dias utilizando-se armadilha Malaise, armadilha Moericke e varredura na vegetação. As famílias de maior abundância relativa foram: Diapriidae (45,92\%), Braconidae (15,00\%), Ichneumonidae (12,92\%) e Platygastridae $(6,15 \%)$. Quatorze famílias tiveram abundância relativa inferior a $1 \%$. Foram registrados na área estudada espécimes de Perilampidae $(0,62 \%)$ e de Pelecinidae $(0,15 \%)$. Este estudo é o segundo levantamento da fauna de himenópteros parasitoides na Serra do Japi.

PALAVRAS-CHAVE: biodiversidade; insecta; Serra do Japi; vespa parasitoide.

\begin{abstract}
This study aimed at surveying the families of parasitic Hymenoptera in the area of the Atlantic Forest in Reserva Municipal Serra do Japi (2313’ 52,24”S, 4656'09,00” W), Jundiai, São Paulo, Brazil. There, 1,300 hymenoptera parasitoids of eight superfamilies and 23 families were collected. The collection was performed for five days using Malaise trap, Moericke trap and "Sweeping" in the Vegetation. Families with the highest relative abundance were: Diapriidae (45.92\%), Braconidae (15,00\%), Ichneumonidae $(12,92 \%)$ and Platygastridae $(6,15 \%)$. Fourteen families showed relative abundance below $1 \%$. The study area registered specimens of Perilampidae $(0,62 \%)$ and Pelecinidae $(0,15 \%)$. This work represents the second survey of the hymenoptera parasitoid fauna in Serra do Japi.
\end{abstract}

KEYWORDS: biodiversity; insecta; Serra do Japi; parasitoid wasp. 
Com grande extensão territorial e detentor de $58 \%$ das florestas da regiáo neotropical, o Brasil é reconhecidamente megadiverso (McNelly et al., 1990). Contudo, grande parte desta biodiversidade foi extinta antes de ser documentada pela ciência, e a maioria ainda por descrever se encontra muito ameaçada (Brown; Brown, 1992). Estima-se que nas florestas tropicais existam entre 5 e 10 milhôes de espécies de insetos, das quais apenas pouco mais de um milhão foi descrita (Godfray et al., 1999; Novotny et al., 2002). Mais da metade de todos os invertebrados descritos são insetos (LaSalle, 1993). Hymenoptera, com 90 famílias, é uma das ordens megadiversas, e suas espécies desempenham importantes funçốes, como a polinizaçáo e o controle de populaçóes de outros artrópodes. Os himenópteros parasitoides participam de mais de $50 \%$ das cadeias alimentares dos ambientes terrestres (LASALLE; GAULD, 1991). A Serra do Japi é considerada prioritária para preservação, pois é uma das últimas grandes áreas de Floresta Atlântica contínua do estado de Sáo Paulo. Embora tenha sofrido alteraçôes antrópicas, ainda apresenta flora e fauna bastante diversas em número de espécies (CARDoso-Leite et al., 2005).

Este é o primeiro levantamento das famílias de himenópteros parasitoides coletados na Serra do Japi. O objetivo deste estudo foi contribuir para o reconhecimento das famílias de himenópteros parasitoides ali presentes e quantificar suas abundâncias relativas por meio de três métodos de coletas.

A Reserva Florestal Serra do Japi $\left(23^{\circ} 13^{\prime}\right.$ 52,24”S, 465'09,00" W) cobre áreas dos municípios de Jundiaí, Cabreúva e Cajamar, no estado de São Paulo, Brasil; com 2,071 ha, a reserva tem cobertura florestal arbórea que se estende de altitudes próximas a $750 \mathrm{~m}$ até $1.294 \mathrm{~m}$, com variaçóes fisionômicas que vão de mata de planalto, formada por árvores espaçadas e de grande diâmetro, a formaçóes de matas com árvores de pequeno porte, densamente distribuídas (Rodrigues; SHePHerd, 1992). Segundo a classificação climática de Koeppen, o clima da região da reserva é do tipo Cwa (temperado úmido com inverno seco e verão quente e úmido); as precipitaçóes máximas ocorrem em janeiro (cerca de $230 \mathrm{~mm} / \mathrm{mês}$ ), e as mínimas, em agosto (cerca de $40 \mathrm{~mm} / \mathrm{mês}$ ).

As coletas foram realizadas durante cinco dias, entre 5 e 9 de fevereiro de 2011. Três métodos de amostragem foram utilizados: armadilha Malaise (TownEs, 1972), armadilha Moericke e varredura na vegetação. Em um ponto de amostragem foi instalada uma armadilha Malaise às $6 \mathrm{~h} 30$ a qual permaneceu coletando até às $18 \mathrm{~h} 30$ do mesmo dia, o material do frasco coletor foi retirado e transferido para um recipiente plástico. Em um transecto de $50 \mathrm{~m}$ foram colocadas 50 armadilhas de Moericke de $15 \mathrm{~cm}$ de diâmetro x 4,5 cm de altura, contendo água, à qual foram adicionadas gotas de detergente. A distância entre as armadilhas era de um metro, as quais permaneceram coletando entre às $6 \mathrm{~h} 30$ até às $18 \mathrm{~h} 30$ do mesmo dia. A varredura da vegetaçẫo foi realizada com rede entomológica, durante 30 minutos, em dois períodos por dia, o primeiro às $6 \mathrm{~h} 30 \mathrm{e}$, o segundo, às $18 \mathrm{~h} 30$. O material obtido foi transferido para sacos plásticos transparentes com algodão embebido em éter em seu interior. Em seguida, foram levados para triagem em laboratório.

A área de amostragem, localizada a cerca de $300 \mathrm{~m} \mathrm{da}$ sede da Reserva, foi a mesma para os três métodos. A triagem dos himenópteros parasitoides foi realizada com auxílio de esteriomicroscópio e, para sua identificação, utilizou-se a chave proposta por HANSON; GAULD 2006; RonQUisT, 1995 e Grissel; Schauff, 1997. Os himenópteros parasitoides coletados foram mantidos em álcool $70 \%$ e depositados no Museu de Zoologia da Universidade Estadual de Campinas (UNICAMP). Foram amostrados 1.300 exemplares de himenópteras parasitoides, de oito superfamílias e 23 famílias (Tabela 1).

Perioto; Lara (2003) e Perioto et al. (2005) obtiveram 23 e 26 famílias de vespas parasitoides em áreas de Mata Atlântica do estado de São Paulo, no Parque Estadual da Serra do Mar e na Estaçáo Ecológica Jureia-Itatins, respectivamente, utilizando armadilhas de Moericke, Malaise e varredura de vegetação. Também em área de mata atlântica, no estado do Espírito Santo, Azevedo et al. (2003) encontraram 35 famílias de himenópteros parasitoides.

A abundância relativa das oito superfamílias de himenópteros parasitoides coletados neste estudo foi a seguinte: Proctotrupoidea (48,77\%), Ichneumonoidea $(27,92 \%)$, Chalcidoidea (8,54\%), Platygastroidea (6,15\%), Cynipoidea (4,08\%), Evanioidea (2,62\%), Crysidoidea (1,46\%) e Ceraphronoidea (0,46\%).

Das 23 famílias encontradas, nove apresentaram maior abundância relativa: Diapriidae (45,92\%), Braconidae (15,00\%), Ichneumonidae (12,92\%), Platygastridae (6,15\%), Figitidae (4,08\%), Eulophidae (3,31\%), Evaniidae (2,62\%), Pteromalidae $(2,62 \%)$ e Proctrotupidae (2,23\%), que correspondem a $94,85 \%$ dos himenópteros capturados.

Foram registradas as presenças de Perilampidae $(0,62 \%)$ e de Pelecinidae $(0,15 \%)$, famílias pouco frequentes em coleções científicas e em amostragens de fauna de parasitoides (Azevedo; Santos, 2000), que Aguiar (2001) classificou como raras e indicadoras de áreas conservadas.

A armadilha de Moericke capturou o maior número de exemplares coletados por família $(66,08 \%)$, seguida pela varredura da vegetaçáo $(28,85 \%)$ e pela armadilha de Malaise $(5,08 \%)$. Neste estudo pode-se dizer que isso ocorreu porque um único exemplar da armadilha Malaise foi colocado no campo, o que poderia explicar a baixa abundância relativa de himenópteros parasitoides capturados em relação ao número total. Diferentemente de Perioto; LARA (2003) este estudo apresentou menor frequência de captura para varredura de vegetação. 
Tabela 1. Abundância das superfamílias e famílias de himenópteros parasitoides amostradas com armadilhas de Malaise, de Moericke e varredura da vegetação na Reserva Municipal Serra do Japi, Jundiaí, SP, entre 5 e 9 de fevereiro de 2011.

\begin{tabular}{|c|c|c|c|}
\hline Superfamília/Família & Total & FRSt & FRFt \\
\hline Ceraphronoidea & 6 & 0,46 & 100,00 \\
\hline Ceraphronidae & 6 & 0,46 & 100,00 \\
\hline Chalcidoidea & 111 & 8,54 & 100,00 \\
\hline Agaonidae & 1 & 0,08 & 0,90 \\
\hline Aphelinidae & 4 & 0,31 & 3,60 \\
\hline Encyrtidae & 1 & 0,08 & 0,90 \\
\hline Eucharitidae & 6 & 0,46 & 5,41 \\
\hline Eulophidae & 43 & 3,31 & 38,74 \\
\hline Eupelmidae & 6 & 0,46 & 5,41 \\
\hline Eurytomidae & 1 & 0,08 & 0,90 \\
\hline Perilampidae & 8 & 0,62 & 7,21 \\
\hline Pteromalidae & 34 & 2,62 & 30,63 \\
\hline Torymidae & 7 & 0,54 & 6,31 \\
\hline Cynipoidea & 53 & 4,08 & 100,00 \\
\hline Figitidae & 53 & 4,08 & 100,00 \\
\hline Crysidoidea & 19 & 1,46 & 100,00 \\
\hline Bethylidae & 11 & 0,85 & 57,89 \\
\hline Chrysididae & 4 & 0,31 & 21,05 \\
\hline Dryinidae & 4 & 0,31 & 36,36 \\
\hline Evanioidea & 34 & 2,62 & 100,00 \\
\hline Evaniidae & 34 & 2,62 & 100,00 \\
\hline Ichneumonoidea & 363 & 27,92 & 100,00 \\
\hline Braconidae & 195 & 15,00 & 53,72 \\
\hline Ichneumonidae & 168 & 12,92 & 46,28 \\
\hline Proctotrupoidea & 634 & 48,77 & 100,00 \\
\hline Diapriidae & 597 & 45,92 & 94,16 \\
\hline Heloridae & 6 & 0,46 & 0,95 \\
\hline Pelecinidae & 2 & 0,15 & 0,32 \\
\hline Proctotrupidae & 29 & 2,23 & 4,57 \\
\hline Platygastroidea & 80 & 6,15 & 100,00 \\
\hline Platygastridae & 80 & 6,15 & 100,00 \\
\hline Total & 1300 & 100,00 & \\
\hline
\end{tabular}

FRSt; frequência relativa dos himenópteros parasitoides em relação ao total coletado; FRFt: frequência relativa das famílias de himenópteros parasitoides em relação ao coletado na superfamília a que pertence.
A armadilha Moericke náo capturou Agaonidae e Eucharitidae, e foi eficiente na captura das demais famílias de himenópteros parasitoides; foi capturado um grande número de Diapriidae (54\% do total coletado), fato que pode estar relacionado ao seu hábito de vida: eles são frequentemente encontrados em áreas sombreadas e muito úmidas, onde buscam hospedeiros sobre a serapilheira (Hanson; GAULD, 2006). Em locais em que as chuvas são constantes, os Diapriideos podem ocorrer durante o ano todo e, onde a estaçấo seca é muito marcada, os adultos de várias espécies emergem no início da estação chuvosa (Hanson; GAULd, 2006). Na Serra do Japi, janeiro é o mês mais quente, com temperaturas médias entre 13,5 e $20,3^{\circ} \mathrm{C}$ e precipitação pluviométrica maior que $250 \mathrm{~mm} / \mathrm{mês}$ (Pinto, 1992). Como as coletas foram realizadas no mês subsequente, portanto ainda com muita umidade e temperaturas elevadas, isso pode explicar a grande abundância relativa de Diapriidae na área de coleta.

Comparando o nosso resultado com o encontrado por Perioto; Lara, 2003, Perioto et al., 2005 e Azevedo; Santos, 2000, observou-se que não houve abundância específica de famílias em função dos métodos empregados. Observaram-se que todos os métodos são complementares e que cada um é capaz de amostrar diferentes frequências relativas de cada superfamília e família presentes na comunidade de parasitoides da Serra do Japi.

\section{AGRADECIMENTOS}

À Coordenação de Aperfeiçoamento de Pessoal de Nível Superior (Capes) e ao Conselho Nacional de Desenvolvimento Cientifico e Tecnológico (CNPq), pelo auxílio financeiro; aos Drs. Eduardo Mitio Shimbori, Helena Carolina Onody e Valmir Antonio Costa pela ajuda na identificação das famílias. A Bruno do Rosário Crespo, pela ajuda no campo, e à Prefeitura de Jundiaí, pela estadia na base da Reserva Florestal Serra do Japi.

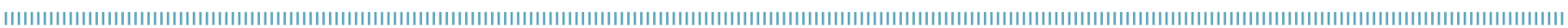

\section{REFERÊNCIAS}

AGUIAR, A.P. Manual de informações sobre conservação e vida silvestre de insetos de Mata Atlântica. São Paulo: publicação autônoma, 100p, 2001.

AZEVEDO, C.O.; SANTOS, H.S. Perfil da fauna de himenópteros parasitoides (Hymenoptera) em uma área de Mata Atlântica da Reserva Biológica de Duas Bocas, Cariacica, ES, Brasil. Boletim do Museu de Biologia Mello Leitão, v. 1 1/12, p. 117 126, 2000.
AZEVEDO, C.O.; CORRÊA, M.S.; GOBBI, F.T.; KAWADA, R.; LANES, G.O.; MOREIRA, A.R.; REDIGHIERI, E.S.; SANTOS, L.M.; WAICHERT, C. Perfil das famílias de vespas parasitoides (Hymenoptera) em uma área de Mata Atlântica da Estação Biológica de Santa Lúcia, Santa Tereza, ES, Brasil. Boletim do Museu de Biologia Mello Leitão, v.16, p.39-46, 2003.

BROWN, K.S.; BROWN, G.G. Habitat alteration and species loss in Brazilian forest. In: Tropical deforestation and species extinction. London: Chapman \& Hall, p.119-142, 1992. 
CARDOSO-LEITE, E.; PAGANI, M.I.; MONTEIRO, R.; HAMBURGER, D.S. Ecologia da paisagem: mapeamento da vegetação da Reserva Biológica da Serra do Japi, Jundiaí, SP, Brasil. Acta botânica. brasilica, v. 19, p.233-243, 2005.

GODFRAY, H.C.J.; LEWIA, O.T.; MEMMOTT, J. Studying insect diversity in the tropics. Philosophical Transactions of the Royal Society, v.354, p.1811-1824, 1999.

GRISSELL, E.E.; SCHAUFF, M.E. Superfamily Chalcidoidea. In: Annotated keys to the genera of Nearctic Chalcidoidea (Hymenoptera). Ottawa: NRC Research Press, p.45-1 16, 1997.

HANSON, P.E.; GAULD, I.D. Hymenoptera de la Región Neotropical. Memories of the American Entomological Institute, v.77, 994p, 2006.

LASALLE, J.; GAULD, I.D. Parasitic Hymenoptera and the biodiversity crisis. Redia, v.74, p.315-334, 1991.

LASALLE, J. Parasitic Hymenoptera, biological control and biodiversity. In: Hymenoptera and Biodiversity. Wallingford: C.A.B. International, p.197-215, 1993.

MCNELLY, J.A.; MILLER, K.R.; REID, W.V.; MITTERMEIER, R.A.; WERNER, T.B. Conserving the world's biological diversity. Washington, D.C.: IUCN, Gland; WRI/Cl/WWF/World Bank, $193 p, 1990$.
NOVOTNY, V.; BASSET, Y.; MILLER, S.E.; DROZD, P.; CIZEK, L. Host specialization of leaf chewing insects in a New Guinea rainforest. Journal Animal Ecology, v.71, p.400-412, 2002.

PERIOTO, N.W.; LARA, R.I.R. Himenópteros parasitoides (Insecta: Hymenoptera) da Mata Atlântica. I. Parque Estadual da Serra do Mar, Ubatuba, SP, Brasil. Arquivos do Instituto Biológico, São Paulo, v.70, n.4, p.441-445, 2003.

PERIOTO, N.W.; LARA R.I.R.; SELEGATTO, A. Himenópteros parasitoides da Mata Atlântica. II. Núcleo Grajaúna, Rio Verde da Estação Ecológica Juréia- Itatins, Iguape, SP, Brasil. Arquivos do Instituto Biológico, São Paulo, v.72, n. 1, p.81-85, 2005.

PINTO, H.S. Clima da Serra do Japi. In: História natural da Serra do Japi. Campinas: Editora da UNICAMP, p.30-49, 1992.

RODRIGUES, R.R.; SHEPHERD, G.H. Análise da variação estrutural e fisionômica da vegetação e características edáficas, num gradiente altitudinal na Serra do Japi. In: História natural da Serra do Japi. Campinas: Editora da UNICAMP, p. 64-97, 1992.

RONQUIST, F. Phylogeny and early evolution of the Cynipoidea (Hymenoptera). Systematic Entomologist, v.20, n.4, p.309-335, 1995.

TOWNES, H. A light-weight Malaise trap. Entomological News, v.83, p.239-247, 1972. 